See Article page 1008.

\section{Reply to Commentary: Can't flow down: More 4-dimensional flow magnetic resonance imaging studies are needed in congenital heart disease}

\author{
Michal Schäfer, $\mathrm{PhD},{ }^{\mathrm{a}} \mathrm{D}$. Dunbar Ivy, $\mathrm{MD},{ }^{\mathrm{a}}$ \\ Alex J. Barker, PhD, ${ }^{b, c}$ and Max B. Mitchell, MD $^{\mathrm{d}}$
}

We thank Dr DeCampli for his thoughtful commentary ${ }^{1}$ considering our study concerning quantitative left ventricular flow analysis in tetralogy of Fallot (TOF). ${ }^{2}$ We agree with his conclusions regarding the ventricular interactions and the need for an early marker for pulmonary valve intervention. DeCampli's comments regarding the limitations of pooled correlative analysis are astute. This analysis is a limitation of our study due to the potential for clustering and confounding. That is why we provided the actual scatter plots to allow readers the opportunity for objective comparison and as a matter of transparency. Our rationale for the combined correlative analysis are 2-fold: to assess the potential relationship across the entire spectrum of participants and to increase the number of observations for meaningful analyses. The first argument was driven purely by the novelty of 4-dimensional flow magnetic resonance imaging markers where normative and disease progression markers are lacking in patients with congenital heart disease. Indeed, the observation that both groups tend to correlate differently suggests that interventricular interaction may be distinct in TOF patients compared with healthy controls. After considering De Campli's comments, we ran the Hotelling $T^{2}$ test and observed that the 2-group stratified

\footnotetext{
From the ${ }^{\mathrm{a}}$ Division of Cardiology and ${ }^{\mathrm{d}}$ Section of Congenital Heart Surgery, Heart Institute, and ${ }^{\mathrm{b}}$ Department of Radiology, Children's Hospital Colorado, and ${ }^{\mathrm{c}} \mathrm{De}-$ partment of Bioengineering, College of Engineering and Applied Sciences, University of Colorado Denver Anschutz Medical Campus, Aurora, Colo.

Disclosures: The authors reported no conflicts of interest.

The Journal policy requires editors and reviewers to disclose conflicts of interest and to decline handling or reviewing manuscripts for which they may have a conflict of interest. The editors and reviewers of this article have no conflicts of interest.

Received for publication March 24, 2020; revisions received March 24, 2020; accepted for publication March 27, 2020; available ahead of print July 3, 2020.

Address for reprints: Michal Schäfer, PhD, Department of Cardiology, Children's Hospital Colorado, 13123 E 16th Ave, Aurora, CO 80045-2560 (E-mail: michal. schafer@cuanschutz.edu).

J Thorac Cardiovasc Surg 2020;160:1019-20

$0022-5223 / \$ 36.00$

Copyright (c) 2020 by The American Association for Thoracic Surgery

https://doi.org/10.1016/j.jtcvs.2020.03.187
}

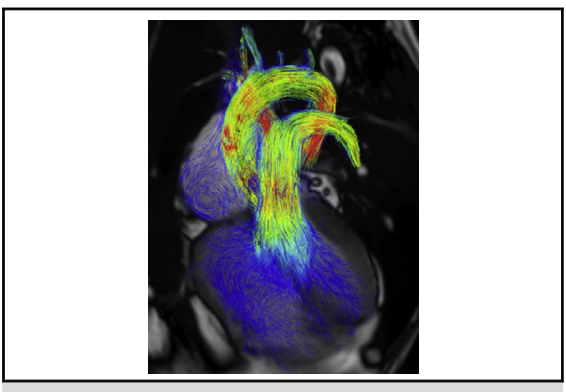

Whole-heart flow visualization of cardiac systole.

\author{
CENTRAL MESSAGE \\ Four-dimensional flow MRI studies \\ in congenital heart disease are \\ scarce, yet they might provide \\ more information than current \\ standard imaging techniques.
}

correlations were statistically different $(P<.05)$. However, we recognize that it is important to acknowledge the limitations of our small sample size where multivariable tests such as Hotelling's may be prone to errors.

Given the early stage of our investigation, we were careful not to draw definitive conclusions and causative correlations between right ventricular size and left ventricular flow hemodynamics. Early detection of left ventricular diastolic dysfunction has been more frequently suggested to be investigated by means of fluid-tissue interactions ${ }^{3}$ and large scale vortex formations ${ }^{4}$ with the premise that changes in the ventricular flow domain would be detectable sooner than early-stage tissue stiffening measured by conventional strain measuring. We continue to recruit patients with repaired TOF to acquire more magnetic resonance imaging-based flow hemodynamic parameters that will continue to inform our knowledge about the complex ventricular interactions in these patients. As we explore this problem further with patients who have more prominent right ventricular dilation, we expect that the relationship between right ventricular dilation and left ventricular flow hemodynamics will hold with improved statistical certainty. At the same time, we urge our colleagues and other investigators to pursue more 4-dimensional flow magnetic resonance imaging studies in patients with congenital heart disease to gain more large-scale, quantitative information. As highlighted previously: Keep those studies flowing. ${ }^{5}$ 


\section{References}

1. DeCampli WM. Commentary: does right ventricular dysfunction cause left ventricular dysfunction in tetralogy of Fallot? The quest continues. J Thorac Cardiovasc Surg. 2020;160:1017-8.

2. Schäfer M, Browne LP, Jaggers J, Barker AJ, Morgan GJ, Ivy DD, et al. Abnormal left ventricular flow organization following repair of tetralogy of Fallot. J Thorac Cardiovasc Surg. 2020;160:1008-15.

3. Schäfer M, Humphries S, Stenmark KR, Kheyfets VO, Buckner JK, Hunter KS, et al. 4D- flow cardiac magnetic resonance-derived vorticity is sensitive marker of left ventricular diastolic dysfunction in patients with mild-tomoderate chronic obstructive pulmonary disease. Eur Hear J Cardiovasc Imaging. 2018; 19:415-24.

4. Pedrizzetti G, La Canna G, Alfieri O, Tonti G. The vortex-an early predictor of cardiovascular outcome? Nat Rev Cardiol. 2014;11: 545-53.

5. Reece TB. Four-dimensional magnetic resonance evaluation of valve preservation: keep those studies flowing. J Thorac Cardiovasc Surg. 2019;157: 466. 